Differences between official inspections and third party audits of food establishments

\title{
Turku, M.
}

2018-03

Turku , M , Lepistö , O \& Lunden , J 2018 , ' Differences between official inspections and third party audits of food establishments ' , Food Control , vol. 85 , pp. 459-465 . https://doi.org/10.1016/j.foodcont.20

http://hdl.handle.net/10138/321878

https://doi.org/10.1016/j.foodcont.2017.10.031

cc_by_nc_nd

acceptedVersion

Downloaded from Helda, University of Helsinki institutional repository.

This is an electronic reprint of the original article.

This reprint may differ from the original in pagination and typographic detail.

Please cite the original version. 
3 Differences between official inspections and third party audits of food

4 establishments

5

6

7 Turku, M. ${ }^{1}$, Lepistö, O. ${ }^{2}$, Lundén $\mathbf{J}^{1 *}$.

$8{ }^{1}$ Department of Food Hygiene and Environmental Health, Faculty of Veterinary Medicine,

9 P.O. Box 66, 00014 University of Helsinki, Finland

$10 \quad{ }^{2}$ Envirovet - Public Health Professionals, P.O. Box 10160, Degerby, Finland

$18 *$ Corresponding author

19 Janne Lundén

Department of Food Hygiene and Environmental Health, Faculty of Veterinary Medicine, P.O.

Box 66, 00014 University of Helsinki, Finland

Tel. +358 294157148

E-mail: janne.lunden@ helsinki.fi 
Abstract

28 Official food control inspections (official inspections) of food establishments and third party audits of food safety management systems (FSMSs) based on international standards both focus on food safety, which has raised discussions on whether FSMSs and their audits could reduce official inspections in food establishments. The aim of this study was to investigate whether the findings of official inspections and third party audits in food establishments are in alignment and to survey the inspectors' and food business operators' (FBOs) perceptions of official inspections and audits. The results can be used in planning the use of audit results as part of official food control. The results show that both inspectors and auditors recognized non-compliances/non-conformities, but significant discrepancies between the findings of official inspections and audits existed, making the utilization of audit results challenging. However, most of the FBOs and inspectors agreed that official inspections and audits overlap, and the majority also agreed that audits of a certified FSMS could under certain circumstances reduce official inspections. system 


\section{Introduction}

Food business operators (FBOs) are responsible for food safety in their establishment (EC, 2002) and are obligated to comply with the general hygiene requirements and Hazard Analysis and Critical Control Point (HACCP) principles stipulated in European Union (EU) regulations (EC, 2004a). FBOs implement self-checking programmes, for example, for sanitation, pest control, traceability and HACCP to fulfil these requirements. The premises and operations, including the self-checking programmes, are regularly inspected by the official food control (food control). In addition to the implementation of the requirements for food safety legislation, many FBOs implement food safety management systems (FSMSs) based on commercial international food safety standards (Lee, 2006; Trienekens \& Zuurbier, 2008) such as those of the British Retail Consortium (BRC), the International Organization for Standardizations (ISO 22000) and the Food Safety System Certification (FSSC) 22000 (Mensah \& Julien, 2011; Qijun \& Batt, 2016) for food safety reasons and customers' requirements (Crandall, van Loo, O’Bryan, Mauromoustakos, Yiannas, Dyenson, \& Berdnik, 2012; Fulponi, 2006). These standard-based FSMSs are audited by third party auditing bodies, which issue a certificate to the food business upon compliance with the standard (BRC, 2017; FSSC, 2016). Both food safety legislation and standards focus on food safety, and the implementation generates costs for FBOs (EC, 2004a,b; Trienekens \& Zuurbier, 2008). This has raised discussions on the overlapping of official inspections and audits and on whether third party audits of FSMS could have a role in food control (Anonymous, 2013; CFIA, 2016; Martinez, Verbrugge, \& Fearne, 2013; Räsänen \& Vastamäki, 2016; Verbruggen \& Havinga, 2015; Wright, Palmer, Shahriyer, Williams, \& Smith, 2013).

EU legislation states that the food control should take into account the results of quality assurance programmes (EC, 2004b), and some countries have included the possibility to utilize FSMS and the audits of those in food control (Räsänen \& Vastamäki, 2016). In EU 
countries such as Belgium, Denmark, the UK and the Netherlands, the frequency of the official inspections can be reduced according to certain preconditions in food businesses with a certified FSMS (Räsänen \& Vastamäki, 2016). In addition, Canada has declared a policy statement including this possibility (CFIA, 2016), and the US has contemplated a role for third party audits (FDA, 2017), showing that there is a wide interest in taking FSMSs into account in food control. Studies, however, on the comparability of official inspection and audit results have not been published according to the knowledge of the authors.

The utilization of FSMSs and their results in food control has raised concerns due to differences in the practices between food control and third party audits (Martinez et al., 2013; Wright et al. 2013; Räsänen and Vastamäki, 2016). Audits are carried out at least annually (FSSC, 2016; GFSI, 2011), and the FBO is usually aware of the audit well in advance, but most of the official inspections must be carried out unannounced. Furthermore, food control is risk based, which means that the risks involved with food operations influence the frequency of the official inspections (EC, 2004b; Evira, 2017). A major difference is that food control is independent from the food businesses, with the primary aim of safeguarding consumers (EC, 2004b), whereas the certification bodies are part of the market economy (Martinez et al., 2013). Economic interest involved with private standards may cause risks (Martinez et al., 2013) and, for example, has led to speculation on whether non-compliances could go unnoticed (Verbruggen \& Havinga, 2015). In slaughterhouses in the Netherlands meat safety was considered to have decreased as a consequence of increasing the responsibility of the FBOs, but decreasing official control (Anonymous, 2014). Because the use of FSMSs and audits of those in food control raises such questions, it is important to investigate the comparability of official inspection and audit results.

The aim of our study is to investigate whether the findings of official inspections and third 
party audits in food premises are in alignment with the special focus on non-compliances

106 observed in official inspections and non-conformities in audits. Furthermore, we will

107 investigate the perceptions of FBOs and local food control inspectors (inspectors) of official 108 inspections and audits. The results can be used in developing the utilization of audits of 109 FSMSs in food control.

\section{2. Material and methods}

\section{2.1. Official inspection and audit reports}

113 Food establishments that were members of the Finnish Food and Drink Industries' Federation

114 were asked to participate in the study. Only food establishments that could provide both 115 official inspection and audit reports from a one- to two-year period were included. Ten food 116 establishments provided the data required (Table 1). The data comprised 66 official inspection 117 and 18 audit reports. The official inspections and audits were conducted between the years 1182013 and 2015. Among the 10 establishments, the certified FSMS based on ISO 22000 was

119 the most frequent (Table 1). The official inspections were performed by different inspectors in 120 different local food control units. The audits were performed by four international audit 121 organisations and seven different auditors.

The inspected and audited issues were divided into 21 categories (Fig. 1). Observed noncompliance or non-conformity and possible time-limits for correction of those were detected

125 from the official inspection and audit reports. The depth of the official inspection or the audit 126 was not assessed because the official inspection and audit reports did not consequently 127 describe how the official inspections or audits were performed, how thoroughly an area was 128 covered and what kind of inspection and audit techniques were used. This study did not 129 compare whether the legislation and the standards contained the same requirements, but 130 focused on comparing official inspections and audits based on the reports. 


\subsection{Questionnaire for inspectors and FBOs}

132 Local food control inspectors' and FBOs' views on food safety legislation and standards and

133 official inspections and audits were inquired in spring 2015 with an electronic questionnaire

134 (E-lomake, Eduix Oy). The questionnaire was sent to all local food control units in Finland

135 (62 units) and to the members of the Finnish Food and Drink Industries' Federation (260

136 companies). The name of the local food control unit was not enquired to ensure the

137 confidentiality of the responding inspectors. Therefore, the response rate was not possible to

138 calculate. The FBOs were instructed to provide answers from only one person per food

139 business. The FBOs were asked about the production type, the number of personnel $(<10,10$ -

$14049,50-249, \geq 250)$ to describe the size of the establishment, and the existence of a certified

141 FSMS at the food establishment. Sections for both respondent groups included the

142 respondents' knowledge and perceptions of legislation and standards and views on the

143 overlapping of official inspections and audits. The FBOs were further asked about the

144 expertise of the inspectors and auditors and the impact of the official inspections and audits.

145 The questionnaire consisted of multiple-choice questions and open-ended questions. The

146 multiple-choice questions followed a four-step Likert scale (totally disagree, somewhat

147 disagree, somewhat agree, totally agree). The impact of the official inspections and audits on

148 food safety risk management was measured on a four-step scale (not at all, somewhat, clearly,

149 very clearly). One reminder was sent.

\section{$151 \quad$ 2.3. Statistical analysis}

152 We employed SPSS 22.0 (IBM, USA) software for a quantitative statistical analysis. The

153 difference in the occurrence of non-compliances and non-conformities was tested with the

154 Fisher exact test, which is applied in dichotomous values. The significance of the differences

155 between the answers of the inspectors and FBOs were tested with the Mann-Whitney test

156 (suitable for testing the difference between two groups), and the significance of the number of 
personnel with the Kruskall-Wallis test (suitable for testing the difference between several

158 groups). Both tests are nonparametric and can be used for small sample sizes. The differences

159 in the opinions of the FBOs representing establishments handling food of animal origin or

160 other establishments was also tested the with Mann-Whitney test. The Wilcoxson Signed

161 ranks test, which is used to testing the distribution of dependent samples, was applied for the

162 FBOs' assessment of the inspections and audits. The statistical significance was considered at

$16395 \%$ confidence intervals $(\mathrm{p}<0.05)$.

164

165 3. Results

166 3.1. Non-compliances/non-conformities observed in official inspections and audits

167 The frequency of non-compliances/non-conformities varied greatly between the official

168 inspections and audits according to the reports (Fig. 1). The official inspection reports

169 contained significantly more remarks on non-compliance concerning cross-contamination,

170 maintenance, hygienic working methods, sanitation and sampling than the audit reports on

171 non-conformities $(\mathrm{p}<0.05$ ), (Fig. 1). In some categories, such as HACCP and recall, the

172 frequency of non-conformities was higher in the audits than of non-compliances in official

173 inspections, although the difference was not statistically significant (Fig. 1).

174

175 Time limits for the correction of non-conformities was set on every non-conformity observed

176 at the audits, according to the reports. The frequency of setting time limits for non-

177 compliances observed in official inspections varied greatly. Most frequently a time limit was

178 set for the correction of non-compliances concerning by-products (50\%), waste management

$179(33 \%)$, maintenance (26\%), sanitation (25\%) and separation of hygiene areas (25\%). No time

180 limits were set for non-compliances such as hygienic working methods or temperature control

181 according to the reports.

182 
185 The number of responding inspectors from local food control units was 28 and of the 260 members of Finnish Food and Drink Industries’ Federation, 42 (response rate 16\%). Among these FBOs 74\% (31/42) had a certified FSMS (Table 2). One of the FBO's FSMS was based on BRC, while 28 FBOs that specified their FSMS relied on ISO 22000 and 19 FBOs on FSSC 22000. Both FBOs handling products of animal origin and other food establishments were represented among the respondents (Table 2). The size of the food establishments according to the number of personnel was as follows: 50-249 (55\%), 10-49 (21\%), > 250 $(19 \%)$ and $<10$ persons $(5 \%)$.

All but one $\operatorname{FBO}(97 \%, 37 / 38)$ and half of the inspectors $(50 \%, 14 / 28)$ reported to have at

195 least some knowledge of a food safety standard. The most commonly known standard among FBOs and inspectors was ISO 22000 (90\% and 29\% were familiar with the standard respectively). However, most of the inspectors (86\%) stated that they need more information about food safety standards, and 33\% reported that they need more information concerning

199 food safety legislation. Among the FBOs, 46\% needed more information on food safety

200 legislation and its implementation (Table 3). There were no significant differences in the answers of the FBOs according to the size of the food business.

\subsection{Overlapping of food safety legislation and standards}

204 The majority of inspectors and FBOs evaluated that food safety is sufficiently included in 205 food safety legislation (96\% and 98\% respectively) and in the official inspections (100\% and 206 95\% respectively) (Table 3). The majority of inspectors and FBOs assessed that standards and 207 audits include food safety sufficiently; however, significantly fewer inspectors than FBOs 208 were of this opinion $(\mathrm{p}<0.001)$ (Table 3). All of the inspectors and the majority of the FBOs 
(90\%) totally or partly agreed that food safety legislation and standards overlap, and the

210 majority of the respondents assessed that the inspectors inspect and the auditors audit same

211 issues (Table 3). No significant differences were observed in the answers between

212 establishments of different sizes or the existence of a certified FSMS or not.

214 The FBOs and especially the inspectors stated that inconsistencies exist in the demands of the 215 inspectors and auditors ( $\mathrm{p}<0.001)$ (Table 3). Interestingly, the analysis showed that the FBOs 216 with a certified FSMS reported significantly fewer inconsistencies $(21 \%, 6 / 28)$ than the FBOs with no certified FSMS $(100 \%, 10 / 10)(\mathrm{p}<0.001)$. The analysis showed that inspectors with no knowledge of a food safety standard were of the opinion that there were more inconsistencies than inspectors with at least some knowledge (93\%, 13/14 and 67\%, 8/12, respectively), although the difference was not statistically significant $(\mathrm{p}>0.05)$. Unfortunately, only a few respondents specified how the demands were inconsistent. One FBO commented that the auditor's approach is more theoretical than the inspector's, and one inspector stated that the auditor requires more in general, but not concerning production 224 hygiene issues.

Almost all respondents agreed totally or partly that a certified FSMS could reduce official inspections (Table 3). Both FBOs (11/42) and inspectors (3/28) commented that the frequency of official inspections or inspection time could be reduced (Table 3). However, two inspectors stated that any reductions in official inspections should be preceded by an evaluation of how the FSMS meets the food safety legislation requirements and that the inspector should have 231 access to the criteria used in audits. 
The FBOs evaluated the auditors' and inspectors' expertise on food safety legislation as good

236 on average (mean 3.5 and 3.4 respectively) (Fig. 2). Most of the FBOs also totally or partly agreed that auditors and inspectors interpret the requirements of the food safety legislation in a practical way (mean 3.6 and 3.1 respectively) ( $<<0.01$ ). The FBOs handling food of animal origin assessed the expertise in food safety legislation and the ability to interpret the requirements of the legislation in a practical way better than the FBOs representing other food establishments (Fig. 2). This difference between the establishments handling food of animal origin and other establishments was significant concerning the inspectors' expertise on food safety legislation $(\mathrm{p}=0.046)$ and the auditors' expertise on interpreting the requirements of the legislation in a practical way $(\mathrm{p}=0.047)$. No significant differences in the answers were observed between the size of the food businesses.

The FBOs evaluated that audits (100\% of the FBOs) and official inspections (90\% of the FBOs) had improved food safety risk management (Wilcoxon signed ranks test, $\mathrm{p}<0.001$ ). The food risk management had improved very clearly due to audits, as reported by $30 \%$ of the FBOs, and official inspections, as reported by $15 \%$ of the FBOs (Fig. 3). The majority of the FBOs' totally or partly agreed that auditors' and inspectors' demands to correct nonconformities/non-compliances were easy to fulfil (84\%, 26/31 and 69\%, 23/33 respectively) (Wilcoxon signed ranks test $\mathrm{p}>0.05$ ).

\section{Discussion}

The study reveals differences between official inspections and audits, which are important to take into account when assessing the utilization of audit results in food control. It is especially important to acknowledge that there were significant differences in the observation of noncompliances in official inspections and non-conformities in audits. The differences were 
observed in important self-checking categories, for example, maintenance of the premises and

261 sanitation, which may have serious consequences on food safety.

263 The observed differences can be due to many reasons, such as the inspectors' and auditors' 264 ability to recognize non-compliances/non-conformities. Discrepancies between official 265 inspections (Läikkö-Roto, Mäkelä, Lundén, Heikkilä, \& Nevas, 2015) and between audits 266 (Albersmeier, Schulze, Jahn, \& Spiller, 2009) have been observed earlier, but differences in 267 observations between official inspections and audits on site have not been investigated before. Differences in the observation of non-compliances and non-conformities can also arise from the fact that official inspections and audits were not performed at the same time and are a snapshot of a specific point in time (Jacxsens, Kirezieva, Luning, Ingelrham, Diricks, \& Uyttendaele, 2015). It is normal that non-compliances occur and are corrected, which means that the situation in the establishment is not identical from one day to another. However, the differences observed in this study were major, the extent and magnitude of the observed differences were surprising, and it is not likely that they can be solely explained by different on-site visit times.

Another factor that can affect the results is the unexpectedness of the official inspections or the expectedness of the audits. Most of the official inspections must be unannounced, but audits have been announced in advance, which may influence the authenticity of the situation 280 at the establishment. To overcome this issue, the conduction of unannounced audits is also 281 being included as a requirement in some standards (Räsänen \& Vastamäki, 2016). Further, it 282 can be hypothesised that the expertise of the inspectors and auditors and time available for carrying out official inspections and audits may influence the outcome. Whatever the reasons are for the discrepancy observed between official inspections and audits, it makes comparison of the official inspection and audit results difficult, which poses a challenge to the utilization 
of audit reports in food control. Actions to decrease discrepancies could include, for example,

287 joint visits of inspectors and auditors to establishments and availability of the criterion that the auditors use, when assessing findings, to inspectors.

The majority of inspectors stated that there are inconsistencies between the demands of the inspectors and auditors. However, only few inspectors specified what the inconsistencies were, suggesting that most of the inspectors do not have any concrete examples of inconsistent demands. Further, all FBOs not having a FSMS agreed that there are inconsistencies, whereas most of the FBOs that did have a certified FSMS did not agree. These results indicate that inspectors and FBOs not familiar with the topic have a strong impression of audits and official inspections being inconsistent, although in reality this might not always be the case.

Most of the FBOs with a certified FSMS and those few inspectors with some knowledge of a food safety standard agreed that food safety legislation and standards overlap. This is not surprising since most of the respondents also assessed that food safety is sufficiently included 302 in both food safety legislation and standards. Consequently, the majority also agreed that a

303 certified FSMS could reduce official inspections or inspection categories. It seems therefore that Finland has a willingness to utilize the results of audits in official control, as in many

305 other countries (FDA, 2017; Räsänen \& Vastamäki, 2016). Suggestions, however, to reduce 306 the frequency of official inspections or reduce control of certain inspection categories should 307 not be made unless the reasons for the discrepancies between official inspection and audit 308 results are investigated. At the moment audit results are not actively utilized in food control in 309 Finland, such as, for example, in Belgium and Denmark (Räsänen \& Vastamäki, 2016). 310 However, audits can indirectly influence official inspection results in Finland; if audits result 311 in higher compliance towards food safety legislation, it can lead to decreased inspection 
314 Both official inspections and audits appear to be important for food safety, as they have impacted food safety risk management according to the FBOs. This finding is in line with previous findings suggesting that official control and certified FSMS improve food safety (Dzwolak, 2016; Escanciano \& Santos-Vijande, 2014; Kettunen, Nevas, \& Lundén, 2015;

318 Nevas, Kalenius, \& Lundén, 2013; Psomas \& Kafetzopoulos, 2015; Qijun \& Batt, 2016).

319 Audits were assessed in this study to have impacted risk management more than official inspections. The reasons for this were not revealed, but it is possible that longer audit visits compared to shorter official inspections, the content of the audits and official inspections, or the competence of the auditors and inspectors have influenced the FBOs' perceptions of the 323 impact.

The fact that both inspectors and auditors found non-compliances and non-conformities in food establishments is of concern; however, it is not uncommon to find non-compliances in official inspections (Läikkö-Roto et al., 2015; Guiducci, Copeland, Dorsey, \& Edelstein, 2011). This indicates that external control is warranted in food establishments, although the FBOs carry the responsibility for the safety of the products. It can also be speculated that more efficacious enforcement measures should be applied due to the high frequency of noncompliances. Time limits for the correction of non-conformities were set systematically in the audits, but in the official inspections time limits were not often used or they were at least not documented. It is possible that some of the non-compliances, for instance, non-compliances

334 concerning hygienic working methods, were requested to be corrected immediately at the 335 official inspection, and therefore a time limit was not documented. The use of time limits is of 336 great importance because they improve the correction of non-compliances (Läikkö-Roto et al., 2015; Luukkanen \& Lundén, 2016). 
339 The FBOs agreed that inspectors and auditors have good expertise in food safety legislation 340 and also assessed positively on average the ability of especially the auditors but also the 341 inspectors to interpret legislative requirements. This is important because it has been shown 342 that FBOs appreciate assistance in interpreting the requirements of legislation (Buckley, 2015; 343 Kettunen, Lundén, Läikkö-Roto, \& Nevas, 2017). In this study almost half of the FBOs stated

344 that they need even more information about food safety legislation and its implementation, 345 which is a challenge for inspectors, auditors and possible other players in the field. 346 Interestingly, differences between the opinions on expertise and the ability to interpret 347 requirements in a practical way were seen between the FBOs handling food of animal origin 348 and the other FBOs. The reason for this was not revealed in this study, but it can be 349 hypothesized that the inspectors and auditors visiting establishments handling food of animal origin have more in-depth training due to the risks involved with animal-derived products.

352 The results of this study concerning official inspection and audit reports can be generalized to other establishments with some limitations. The number of included establishments was rather

354 small, but the establishments represented different production types, and the official 355 inspections and audits were carried out by several inspectors and auditors. The discrepancies 356 between the findings of inspectors and auditors were also quite striking. The results of the 357 questionnaire must be interpreted carefully because of the scarce number of respondents. The 358 number of responding inspectors is modest, presumably because very few have knowledge of 359 food safety standards. All of the responding FBOs were members of the Finnish Food and 360 Drink Industries' Federation, and therefore we do not know if FBOs that are not members 361 would show a similar answering profile. However, most of the responding FBOs had a 362 certified FSMS. Therefore, we hypothesize that these results can be generalized better to FBOs with a certified FSMS. 
364 In conclusion, official inspections and audits overlap, and both inspectors and FBOs agree

365 that audits of certified FSMSs could somehow reduce official control. However, this study

366 shows striking differences in the observations in official inspections and audits, which makes

367 the comparison of official inspections and audits challenging. The development of a

368 utilization scheme of audit results as part of food control requires a better understanding of

369 the reasons leading to discrepancies between audit and official inspection results.

371 Acknowledgements

372 The study was supported by the Agency for Rural Affairs.

\section{References}

375 Albersmeier, F., Schulze, H., Jahn, G., \& Spiller, A. (2009). The reliability of third-party

376 certification in the food chain: From checklists to risk-oriented auditing. Food Control, 20, 927-935. https://doi.org/10.1016/j.foodcont.2009.01.010

Anonymous. (2013). Study to evaluate the effectiveness of independently accredited assurance schemes and the role they could play in the delivery of official controls at UK

381 points of entry. FS 204009, 20.th September, ICF GHK.

382 https://www.food.gov.uk/sites/default/files/841-1-

383 1541_FS204009_FSA_assurance_schemes_final_report_201113_SMc-.pdf

384 Accessed 13.9.17.

386 Anonymous. (2014). Summary: Risks in the meat supply chain. The Hague, March 2014

387 http://www.onderzoeksraad.nl/uploads/phase-docs/560/38357a3466aerisico-s-vleesketen-en-

$388 \quad \underline{\text { web.pdf }}$

389 Accessed 13.9.17. 
391 BRC. (2017). Global standard. Food safety.

392 https://www.brcglobalstandards.com/media/27116/brc-food-7-quick-guide-uk-screen.pdf 393 Accessed 13.9.17.

394

395 Buckley, J. (2015). Food safety regulation and small processing: A case study of interactions

396 between processors and inspectors. Food Policy. 51, 74-82.

397 https://doi.org/10.1016/j.foodpol.2014.12.009

398

399 CFIA. (2016). Private Certification Policy (Food Safety). Canadian Food Inspection Agency.

$400 \quad$ 14.1.2016.

401 http://www.inspection.gc.ca/about-the-cfia/accountability/consultations-and-

402 engagement/regulatory-risk-based-oversight/private-certification-

403 policy/eng/1452808755126/1452808821799

404 Accessed 13.9.17.

405

406 Crandall, P., van Loo, E. J., O’Bryan, C. A., Mauromoustakos, A., Yiannas, F., Dyenson, N., 407 \& Berdnik, I. (2012). Companies' Opinions and Acceptance of Global Food Safety Initiative 408 Benchmarks after Implementation. Journal of Food Protection, 75, 1660-1672. 409 http://doi.org/10.4315/0362-028X.JFP-11-550

411 Dzwolak, W. (2016). Assessment of food allergen management in small food facilities. Food 412 Control, 73, 323-331. http://doi.org/10.1016/j.foodcont.2016.08.019

414 EC. (2002). Regulation (EC) No 178/2002 of the European Parliament and of the Council of 41528 January 2002 laying down the general principles and requirements of food law, 
416 establishing the European food safety authority and laying down procedures in matters of

417 food safety. Official Journal of the European Communities, L31, 1.

418

419 EC. (2004a). Regulation (EC) No 852/2004 of the European Parliament and of the Council of 29 April 2004 on the hygiene of foodstuffs. Official Journal of the European Union, L226, 3.

421

EC. (2004b). Regulation (EC) No 882/2004 of the European Parliament and of the Council of

29 April 2004 on official controls performed to ensure the verification of compliance with

food and feed law, animal health and animal welfare rules. Official Journal of the European

Communities, L165, 1.

426

Escanciano, C., \& Santos-Vijande, M. L. (2014). Reasons and constraints to implementing an

ISO 22000 food safety management system: Evidence from Spain. Food Control, 40, 50-57.

http://doi.org/10.1016/j.foodcont.2013.11.032

Evira. (2017). Risk classification of food premises and determination of inspection frequency.

432 Finnish Food Safety Authority.

433 https://www.evira.fi/globalassets/tietoa-evirasta/julkaisut/oppaat/eviran_ohje_10503_2_fi.pdf

434 Accessed 13.9.17.

436 FDA. (2017). Third-party audits and FSMA. U.S. Food and Drug Administration.

437 https://www.fda.gov/Food/GuidanceRegulation/FSMA/ucm543296.htm

438 Accessed 13.9.17.

440 FSSC. (2016). FSSC 22000. Global certification scheme for food safety management 441 systems. 
442 http://www.fssc22000.com/documents/pdf/brochure/brochure-fssc-22000-versie-c-2016.pdf

443 Accessed 13.9.17.

444

445 Fulponi, L. (2006). Private voluntary standards in the food system: the perspective of major 446 food retailers in OECD countries. Food Policy, 31, 1-13.

447 https://doi.org/10.1016/j.foodpol.2005.06.006

449 GFSI. (2011). Enhancing food safety through third party certification. Global Food Safety 450 Initiative.

451 http://www.mygfsi.com/images/mygfsi/gfsifiles/information-kit/GFSI_White_Paper_-

452 Enhancing_Food_Safety_Through_Third_Party_Certification.pdf

453 Accessed 13.9.17.

454

455 Guiducci, G., Copeland, F, Dorsey, T., \& Edelstein, S. (2011). A rewiev of the food 456 establishment inspection reports in Boston, Massachusetts. Topics in Clinical Nutrition, 26, $457 \quad 165-170$.

459 Jacxsens, L., Kirezieva, K., Luning, P. A., Ingelrham, J., Diricks, H. \& Uyttendaele, M. 460 (2015). Measuring microbial food safety output and comparing self-checking systems of food 461 business operators in Belgium. Food Control, 49, 59-69.

462 https://doi.org/10.1016/j.foodcont.2013.09.004

463

464 Lee, G. C-H. (2006). Private Food Standards and their Impacts on Developing Countries.

465 European Commission DG Trade Unit G2, available at

466 http://trade.ec.europa.eu/doclib/docs/2006/november/tradoc_127969.pdf. 
Kettunen, K., Lundén, J., Läikkö-Roto, T., Nevas, M. (2017). Towards more consistent and 469 effective food control: learning from the views of food business operators. Int. J. Environ. Health Res. http://dx.doi.org/10.1080/09603123.2017.1332351

471

472 Kettunen, K., Nevas, M., \& Lundén, J. (2015). Effectiveness of enforcement measures in 473 local food control in Finland. Food Control, 56, 41-46.

474 http://doi.org/10.1016/j.foodcont.2015.03.005

475

476 Luukkanen, J. \& Lundén, J. (2016). Compliance in slaughterhouses and control measures 477 applied by official veterinarians. Food Control, 68, 133-138. 478 https://doi.org/10.1016/j.foodcont.2016.03.033

480 Läikkö-Roto, T., Mäkelä, S., Lundén, J., Heikkilä, J. \& Nevas, M. (2015). Consistency in 481 inspection processes of food control officials and efficacy of official controls in restaurants in 482 Finland. Food Control, 57, 341-350. https://doi.org/10.1016/j.foodcont.2015.03.053

Martinez, M. G., Verbruggen, P. \& Fearne, A. (2013). Risk-based approaches to food safety regulation: what role for co-regulation? Journal of Risk Research, 16, 1101-1121. http://dx.doi.org/10.1080/13669877.2012.743157

Mensah, L. D., \& Julien, D. (2011). Implementation of food safety management systems in the UK. Food Control, 22, 1216-1225. http://doi.org/10.1016/j.foodcont.2011.01.021

491 Nevas, M., Kalenius, S., \& Lundén, J. (2013). Significance of official food control in food 492 safety: Food business operators' perceptions. Food Control, 31, 59-64. 493 http://doi.org/10.1016/j.foodcont.2012.09.041 
495 Psomas, E. L., \& Kafetzopoulos, D. P. (2015). HACCP effectiveness between ISO 22000

496 certified and non-certified dairy companies. Food Control, 53, 134-139.

497 http://doi.org/10.1016/j.foodcont.2015.01.023

498

499 Qijun, J., \& Batt, P. J. (2016). Barriers and benefits to the adoption of a third party certified 500 food safety management system in the food processing sector in Shanghai, China. Food 501 Control, 62, 89-96. http://doi.org/10.1016/j.foodcont.2015.10.020

502

503 Räsänen, L. \& Vastamäki, P. (2016). Utilization of food safety management systems in food 504 control (In Finnish). Elintarvike- ja Terveys. 3, 12-15.

505

506 Trienekens, J., \& Zuurbier, P. (2008). Quality and safety standards in the food industry, 507 developments and challenges. International Journal of Production Economics, 113, 107-122. 508 http://doi.org/10.1016/j.ijpe.2007.02.050

509

510 Verbruggen, P. \& Havinga, T. (2015). Food safety meta-controls in the Netherlands. European

511 Journal of Risk Regulation, 6, 512-524. https://doi.org/10.1017/S1867299X00005079

512

513 Wright, M., Palmer, G., Shahriyer, A., Williams, R., \& Smith, R. (2013). Assessment and 514 comparison of third party assurance schemes in the food sector: Towards a common 515 framework. Final report for the Food Standards Agency CR2435 R2 V8.

516 https://www.food.gov.uk/sites/default/files/835-1-

517 1534_GSB_CR2435_3rd_Party_Assurance_Scheme_R2_V8_FCA.pdf

518 Accessed 13.9.17. 


\section{Highlights}

-Inspectors observed significantly more non-compliances than auditors non-conformities -All inspectors and $90 \%$ of FBOs agree that legislation and standards overlap -The majority of respondents stated that certified FSMSs could reduce inspections -Almost half of the FBOs need more information on food safety legislation 
Figure captions

\section{Figure 1.}

Frequency of non-compliances observed at official inspections $(\mathrm{n}=66)$ and non-conformities at audits $(n=18)$.

$1=$ Cross-contamination $* ; 2=$ Maintenance*; $3=$ Hygienic working methods $*$;=Traceability; $5=$ Contact material; $6=$ Sanitation*; $7=$ Temperature control; $8=$ Pest control; $9=$ Waste management; $10=$ Separation of hygiene areas; 11=Personnel health; 12=Sampling*; 13=Self-inspection documentation; 14=By-products; $15=$ Inspection of received products; 16=HACCP; 17=Reclamations; 18=Recall; 19=Personnel training; 20=Allergen control; 21=Labelling. *Statistically significant difference in the number of non-compliance observed at official inspections and nonconformities observed at audits (Fisher exact test $\mathrm{p}<0.05$ ).

Figure 2.

Food business operators' evaluation of the inspectors' and auditors' expertise in food safety

legislation and their ability to practically interpret the requirements of the legislation.

*Only FBOs with a certified food safety management system answered.

Figure 3.

Food business operators' assessment of the impact of official inspections and audits.

*Only FBOs that had a certified food safety management system answered. 
Figure 1

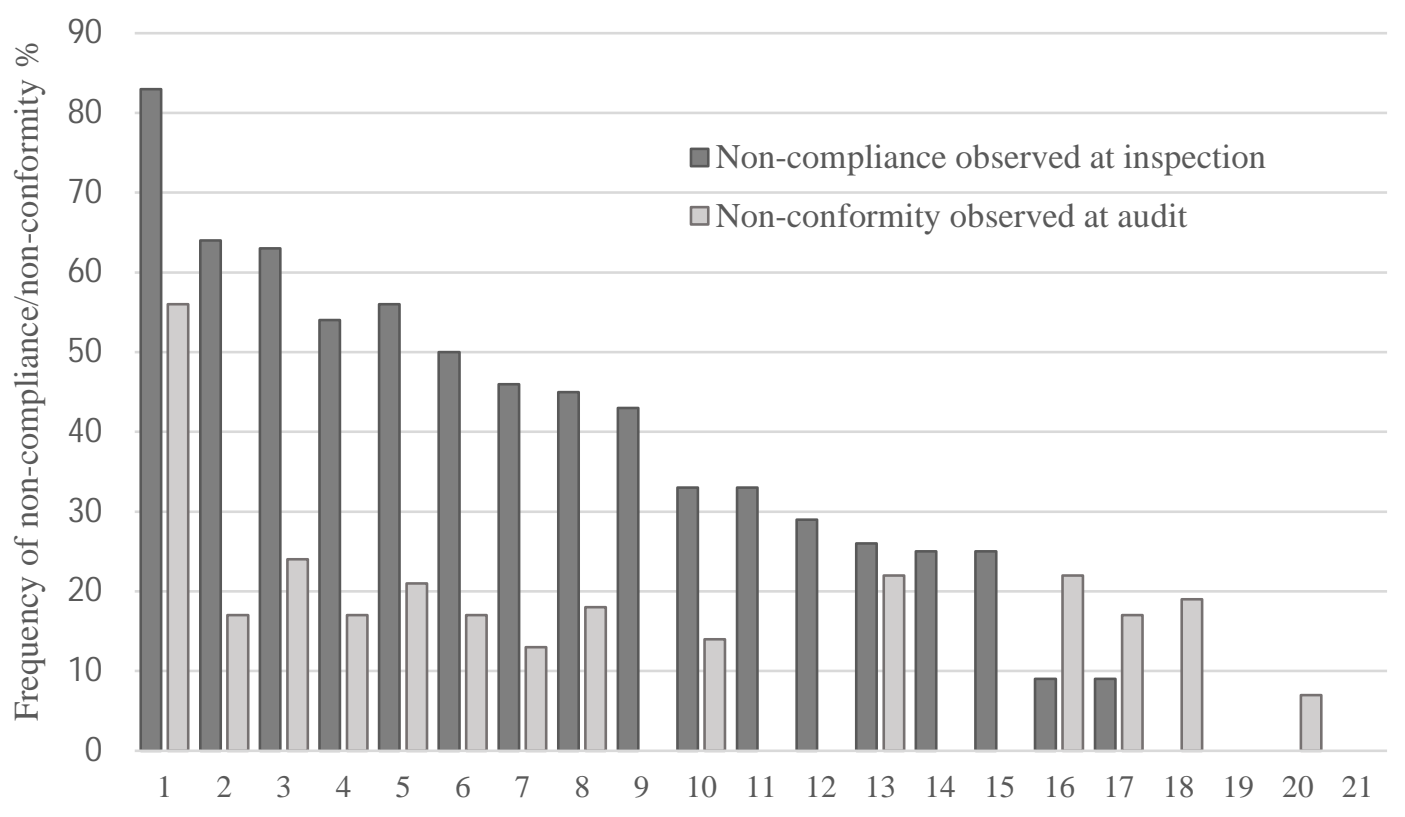


Figure 2.

$\square$ Establishment handling food of animal origin

$\square$ Other food establishment

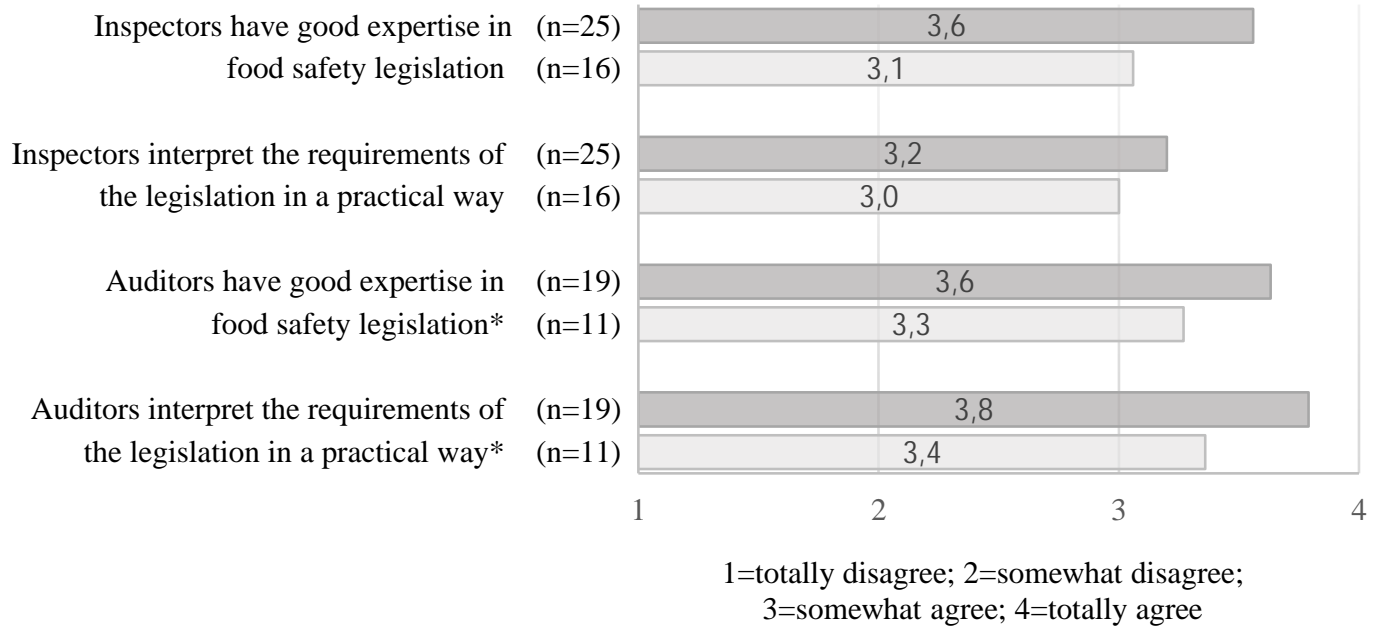


Figure 3

Inspections have improved our food safety risk management $(\mathrm{N}=41)$

Audits have improved our food safety risk management $(\mathrm{N}=30) *$

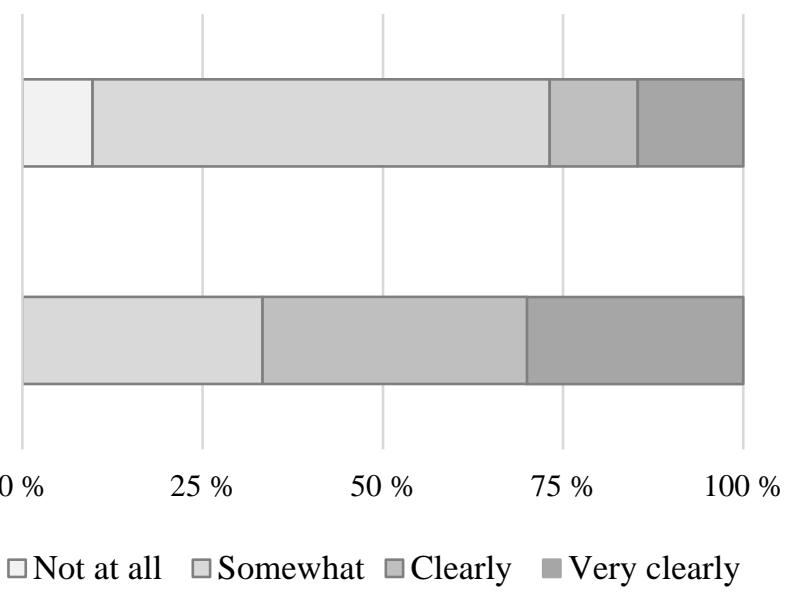


Table 1. Number and type of food establishments that provided official inspection and audit reports for the study.

\begin{tabular}{|c|c|c|c|c|c|c|}
\hline \multirow{2}{*}{$\begin{array}{l}\text { Food business } \\
\text { operator }\end{array}$} & \multirow{2}{*}{$\begin{array}{c}\text { Food } \\
\text { establishment }\end{array}$} & \multirow[t]{2}{*}{ Product type } & \multicolumn{4}{|c|}{ Food safety management system } \\
\hline & & & $\begin{array}{c}\text { ISO } \\
22000\end{array}$ & $\begin{array}{l}\text { ISO TS } \\
22002-1\end{array}$ & $\begin{array}{l}\text { FSSC } \\
22000\end{array}$ & $\mathrm{BRC}$ \\
\hline 1 & 1 & Milk powder & 1 & 1 & & \\
\hline 1 & 2 & Cheese & 1 & 1 & & \\
\hline 2 & 3 & Meat product & 1 & 1 & 1 & \\
\hline 3 & 4 & Ready-to-eat product & 1 & 1 & 1 & \\
\hline 3 & 5 & Ready-to-eat product & 1 & 1 & 1 & \\
\hline 4 & 6 & Bakery product & 1 & 1 & 1 & \\
\hline 5 & 7 & Processed fishery product & 1 & & & \\
\hline 6 & 8 & Meat cutting & 1 & 1 & 1 & \\
\hline 7 & 9 & Processed vegetables & 1 & & & \\
\hline 8 & 10 & Cooking oil & & & & 1 \\
\hline
\end{tabular}


Table 2. Respondent groups and response rates of the questionnaire and the presence of a certified food safety management system (FSMS) in the responding food businesses.

Respondent group

Number of Number of food businesses respondents $(\%) \quad$ with a FSMS $(\%)$

Food control inspector at local unit

$28^{\mathrm{a}}$

$42(16)$

$31(74)$

Food business operator ${ }^{\mathrm{b}}$

Establishment handling food of animal origin

Other food premises ${ }^{\mathrm{c}}$
26

$20(77)$

16
$11(69)$

${ }^{a}$ The questionnaire did not enquire the name of the local food control unit to maintain the anonymity of the inspectors, and therefore the percentage of the responding units cannot be calculated.

'The questionnaire was sent to the members ( $n=260)$ of the Finnish Food and Drink Industries' Federation. The share of establishments handling food of animal origin and other food establishments among the members is not known.

${ }^{\mathrm{c}}$ Premises handling vegetables, baking products, candy, beverages, berries, oil or yeast. 
Table 3. Food business operators' (FBO) and local food control inspectors' views and the educational needs of food safety legislation and standards.

\begin{tabular}{|c|c|c|c|}
\hline \multirow[t]{2}{*}{ Statement } & \multicolumn{2}{|c|}{$\begin{array}{c}\text { Agree completely or partially with } \\
\text { the statement } \\
\%(n / \mathrm{N})\end{array}$} & \multirow[t]{2}{*}{ p-value ${ }^{a}$} \\
\hline & FBOs & $\begin{array}{l}\text { Local food } \\
\text { control }\end{array}$ & \\
\hline \multicolumn{4}{|l|}{ Food safety } \\
\hline Food safety is sufficiently included in food safety standards & $100(39 / 39)$ & $77(10 / 13)$ & $<0.001$ \\
\hline Food safety is sufficiently included in food safety legislation & $98(38 / 39)$ & $96(25 / 26)$ & $>0.05$ \\
\hline Food safety is sufficiently included in audits & $100(39 / 39)$ & $73(8 / 11)$ & $<0.001$ \\
\hline Food safety is sufficiently included in official inspections & $95(37 / 39)$ & $100(26 / 26)$ & $>0.05$ \\
\hline \multicolumn{4}{|l|}{ Overlapping } \\
\hline Requirements of food safety legislation and standards overlap & $90(28 / 31)$ & $100(8 / 8)$ & $>0.05$ \\
\hline Inspectors and auditors inspect/audit the same issues & $81(26 / 32)$ & $89(8 / 9)$ & $>0.05$ \\
\hline Inspectors' and auditors' demands have been inconsistent & $42(16 / 38)$ & $81(21 / 26)$ & $<0.001$ \\
\hline Certified food safety management system could reduce inspections & $93(27 / 29)$ & $89(8 / 9)$ & $>0.05$ \\
\hline \multicolumn{4}{|l|}{ Knowledge and educational needs } \\
\hline I have basic knowledge about at least one food safety standard & $97(37 / 38)$ & $48(13 / 27)$ & $<0.001$ \\
\hline I need more information about food safety standards & $37(15 / 41)$ & $86(24 / 28)$ & $<0.001$ \\
\hline I need more information about food safety legislation and its implementation & $46(19 / 41)$ & $33(9 / 27)$ & $>0.05$ \\
\hline Food control officials need more information about food safety standards & $89(34 / 38)$ & $89(25 / 28)$ & $>0.05$ \\
\hline
\end{tabular}

${ }^{a}$ Statistical significance of the difference between groups was tested with the Mann-Whitney test. 